\title{
LAS REPRESENTACIONES DE LOS ARTRÓPODOS EN LA ARQUEOLOGÍA COLOMBIANA
}

Hugo A. Sotomayor Tribín MD*

\section{Resumen}

Diferentes tipos de artrópodos (miriápodos, crustáceos, insectos, arácnidos) y estadios del desarrollo de los insectos (pupas, larvas, adultos) fueron representados en diferentes materiales como cerámica, piedra y oro, a manera de expresión del conocimiento que los pueblos indígenas tenían y tienen sobre estos animales, y por la asociación que hicieron y hacen de sus características y conductas con la vida y la sociedad humana.

Palabras clave: artrópodos, arqueología, pensamiento analógico, pensamiento analítico, arañas, insectos, escarabajos, mariposas, crisálidas, larvas, pupas.

\section{ARTHROPOD REPRESENTATIONS IN COLOMBIAN ARCHAELOGY}

\section{Abstract}

Different types of arthropods (i.e: myriapods, crustaceous, insects, arachnida) and insect development forms (pupas, larvae, adults) were displayed on various materials including ceramics, stone and gold as an expression of indigenous people ancient and present ideology on these animals and due to metaphors between their characteristics and behavior and life and human society.

Key words: arthropods, archaeology, analogical thought, analytic thought, spiders, insects, beetles, butterflies, chrysalis, larvae, pupas.

\section{Introducción}

Pensamiento analógico, pensamiento analítico: los pueblos indígenas del pasado y presente de lo que hoy es Colombia en virtud del chamanismo y por su estrecha dependencia con las fuerzas de la naturaleza, se valieron de procesos de comparación y analogías sistemáticas entre los diversos aspectos de la vida de los animales, de las plantas, de los seres inanimados y de los aspectos generales de su entorno, para explicar la vida de ellos mismos como individuos y como sociedades. Este tipo de pensamiento de contraste, totalizante, comparativo, asociativo y analógico, es el que en otras perspectivas políticas, históricas y científicas se ha llamado con diferentes nombres como "primitivo" y "mágico", para oponerlo al que hoy se llama científico o analítico.

El pensamiento analógico contrasta entre macho y hembra, arriba y abajo, derecho e izquierdo, día y noche, adelante y atrás, blanco y amarillo; azul y rojo, mate y brillante, pequeño y grande; claro y oscuro; externo e interno; cálido y frío, seco y húmedo, oro y plata, sol y luna, 
presencia y ausencia, duro y blando, dulce y amargo, dócil y díscolo, visibilidad e invisibilidad, vigilia y sueño, volar y reptar, etc. El pensamiento analógico le da un gran valor a la metamorfosis que sufren ciertos animales, como ocurre con algunos insectos y batracios.

Al vivir ellos en una estrecha asociación con el resto de seres de la naturaleza, desarrollaron extraordinarios conocimientos sobre su entorno animal, vegetal y de seres animados, que hoy son aprovechados por los ecologistas y los etólogos. Así, partiendo del pensamiento sistémico, comparativo, ecológico y etológico es como debemos tratar de entender los restos arqueológicos y las mitologías en donde figuran los artrópodos.

Los artrópodos: para efectos de la compresión del texto que sigue es necesario definir qué son los artrópodos y cómo está subdividido este filo de animales. Son un conjunto de invertebrados con un exoesqueleto formado por cutículas y su cuerpo está dividido en una serie lineal de segmentos. A este filo de animales, el más numeroso que existe, pertenecen las siguientes clases: insectos, miriápodos, crustáceos y arácnidos.

Los insectos se caracterizan por tener tres pares de patas y antenas; los miriápodos por muchos pares de patas y antenas; los crustáceos con cinco pares de patas de los cuales el primero puede estar transformado en pinzas, tener antenas y la mayoría de ellos viven en el agua; los arácnidos tienen cuatro pares de patas, el primero puede estar conectado a glándulas venenosas y no tener antenas. Ejemplos de los insectos pueden ser las moscas, mosquitos, saltamontes, mariposas, libélulas, avispas, abejas, hormigas, triatomíneos, cucarrones, pulgas, piojos, etc. Entre los miriápodos están los ciempiés y milpiés; en los crustáceos figuran los cangrejos, camarones, langostinos y las gambas; y entre los arácnidos figuran como ejemplos los escorpiones, arañas, garrapatas, ácaros, etc.

\section{Material}

\section{Las representaciones de los artrópodos y otros animales en las ofrendas votivas y funerarias}

Dentro de las ofrendas que hicieron los diferentes conglomerados indígenas hubo objetos que representaron diferentes animales en forma realista, abstracta o qui- mérica, según el estilo del arte de cada uno de los pueblos. Los diversos grupos que habitaron lo que hoy es Colombia dejaron bellas y realistas representaciones de diferentes animales esculpidas y talladas en oro, hueso, piedras, cerámica, conchas, nácar, etc.

Alrededor de las ofrendas que los indígenas muiscas del altiplano cundiboyacense, Lucas Fernández de Piedrahita, autor de "Noticia Historial de las Conquistas del Nuevo Reino de Granada", escribió:

“... hacían las ofrendas a sus ídolos, de esmeraldas, oro en polvo o en puntas, y así mismo de diferentes figuras de culebras, sapos, lagartijas, hormigas y gusanos; casquetes, brazaletes, diademas, monas, raposas y vasos, todo de oro; ofrecían también tigres, leones y otras cosas de menos importancia, como son pájaros y vasijas de barro, con mantenimiento o sin ellos".

Los artrópodos fueron y son, por su alto valor nutritivo dada su riqueza en proteínas, grasas, vitaminas y minerales, una fuente de alimentación en algunos momentos del calendario ecológico de los indígenas, así como inspiradores de mitologías y elementos reales y figurados de ritos de paso. Al igual que muchos pueblos del pasado y del presente y de diferentes latitudes, los indígenas colombianos le adscribieron al consumo y contacto de los animales, como es el caso de los artrópodos, valores simbólicos especiales según el contexto material, ecológico y cultural de cada uno de esos pueblos.

Las arañas en la mitología muisca lo relató en su obra "Noticias historiales de las conquistas de Tierra Firme en las Indias Occidentales" el cronista Fray Pedro Simón en la siguiente forma:

“... que los muertos han de resucitar y vivir después para siempre en este mismo mundo, de la suerte que ahora viven, porque entienden haber de permanecer siempre este mundo de la manera que ahora lo vemos; que las almas son inmortales y que cuando salen de los cuerpos (que solos mueren), ellas bajan al centro de la tierra por unos caminos y barrancas de tierra amarilla y negra, pasando primero por un gran río en unas barcas o balsas de tela de araña. Y por eso dicen no osan matar- 
las, porque no falte quién los pase. Allá tiene cada cual provincia sus términos y lugares señalados, como acá, donde hallan hechas labranzas, porque en esto no hacen diferencia...".

El autor de estas líneas después de visitar varias veces los Museos del Oro y Arqueológico de la Casa del Marqués de San Jorge, en Bogotá D.C., ver varias colecciones particulares de arte prehispánico colombiano y revisar textos de arqueología colombiana, escogió catorce piezas, ocho de oro y seis de cerámica, que representan artrópodos. El estado adulto se muestra como un insecto en una pieza de oro de la cultura Tolima (Figura 1); en otro insecto en un plato de cerámica Nariño, en unas arañas en dos platos de cerámica de Nariño, en forma esquemática de escorpión en una vasija Tolima y en un escarabajo en una pieza cerámica de la cultura Tairona; la metamorfosis de los insectos está registrada en una pieza de oro de la cultura Tolima que representa ya sea una crisálida de mariposa o una larva de nuche (Figura 2); en dos piezas de oro Tolima como larvas (Figura 3) y en una piedra de la cultura Tairona co-

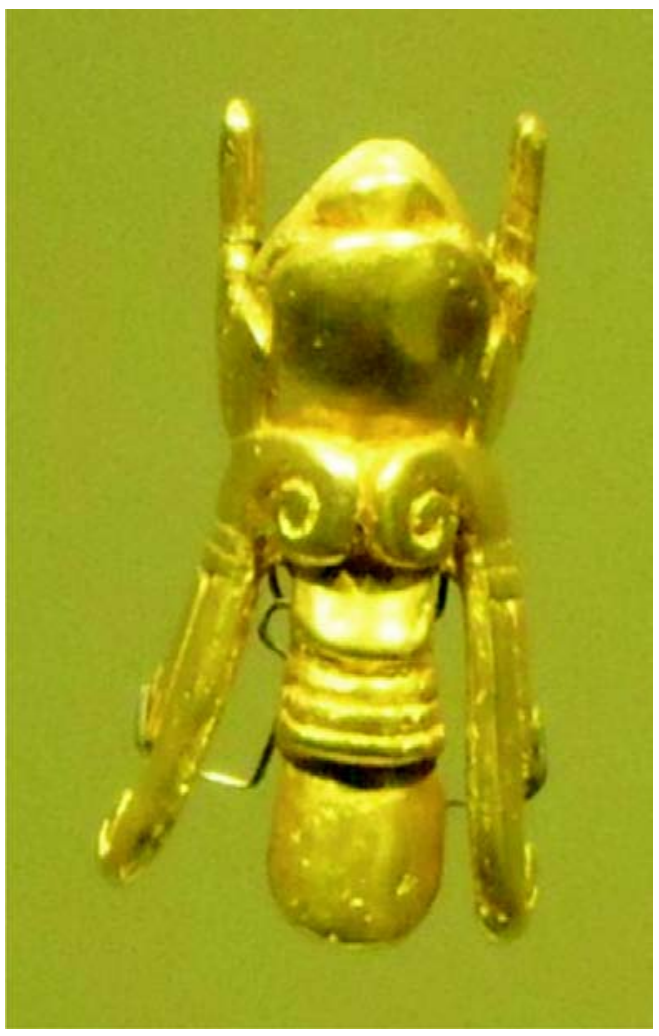

Figura I. Insecto. Cultura Tolima, Museo del Oro, Bogotá D.C.

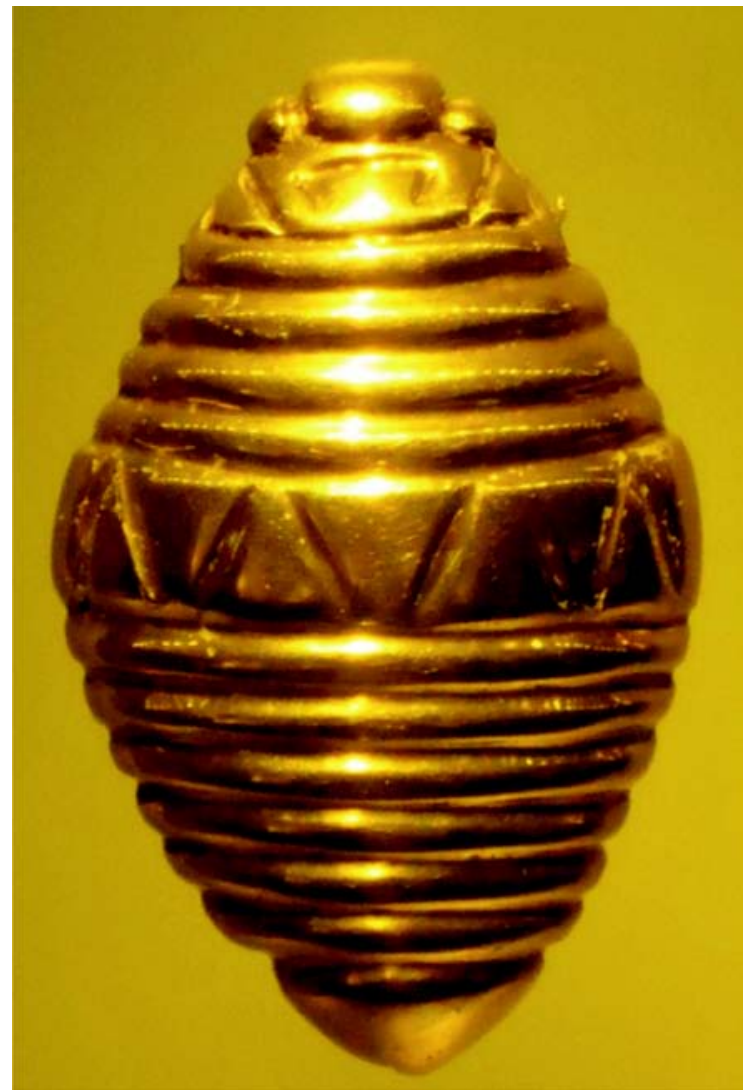

Figura 2. ¿Crisálida de una mariposa en una pieza? ¿Larva de nuche? Pieza de oro de la Cultura Quimbaya, Corinto, Cauca. Museo del Oro, Bogotá D.C.

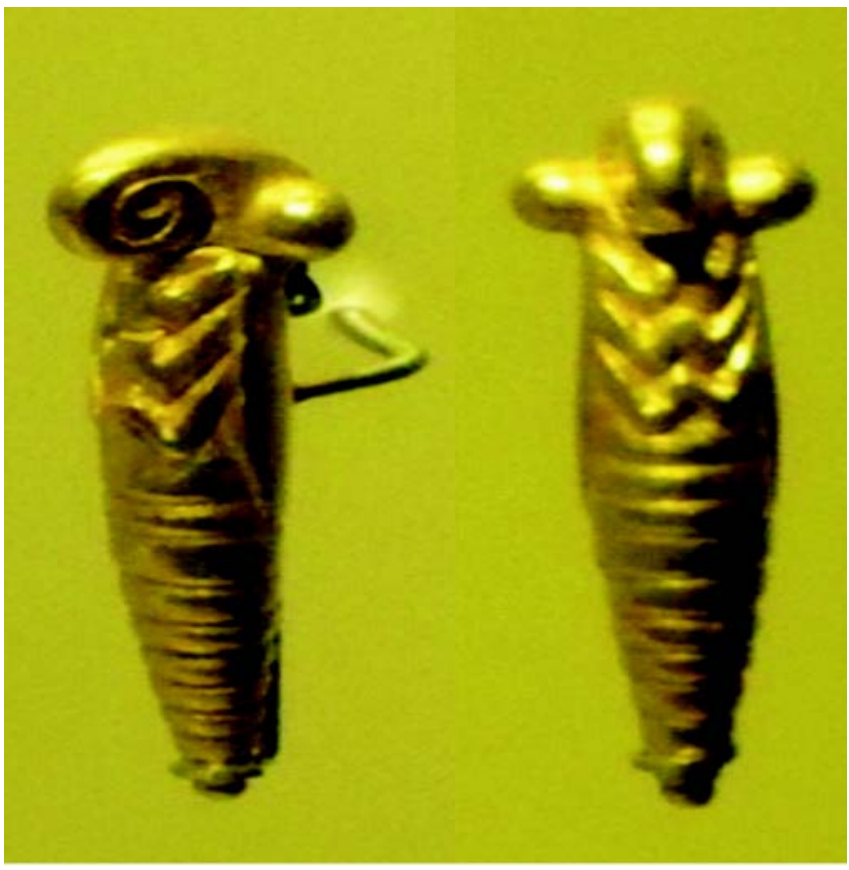

Figura 3. Larvas de insectos. Cultura Quimbaya. Museo del Oro, Bogotá D.C. 
rrespondiente a una pupa. De la cultura Tolima se muestran dos piezas en oro que pueden ser unas quimeras fantásticas o un tipo de lepidópteros, los skipers (Figuras 4 y 5). De la cultura muisca se muestra una pieza en oro que parece corresponder a otra quimera fantástica (Figura 6).

A lado de las anteriores piezas de oro, que se encuentran exhibidas en el Museo del Oro del Banco de la República en Bogotá D.C., se encuentran tres platos funerarios del altiplano nariñense, en especial de su horizonte Tuza, (1250 al 1500 d. C.) con representación en dos de ellos de arañas en su fondo,

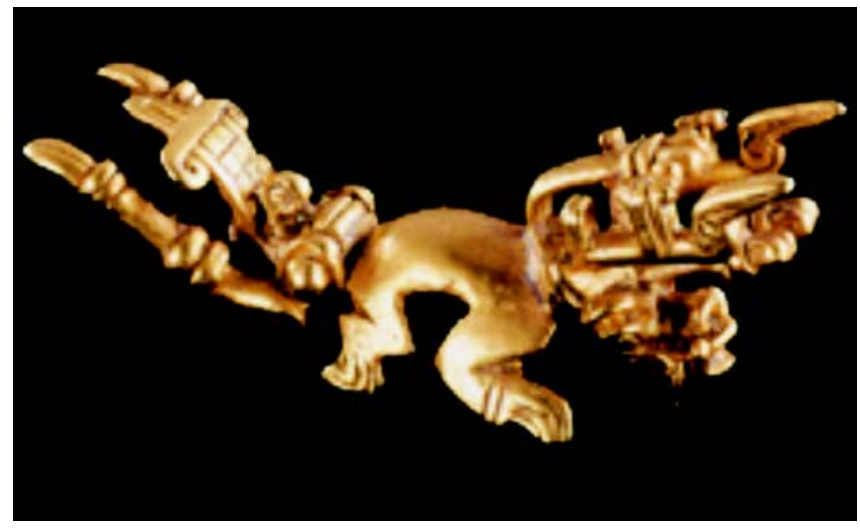

Figura 4. Quimera fantástica de un ser que comparte aspectos de jaguar, pez y quizás un insecto. Cultura Tolima. Museo del Oro, Bogotá D.C.

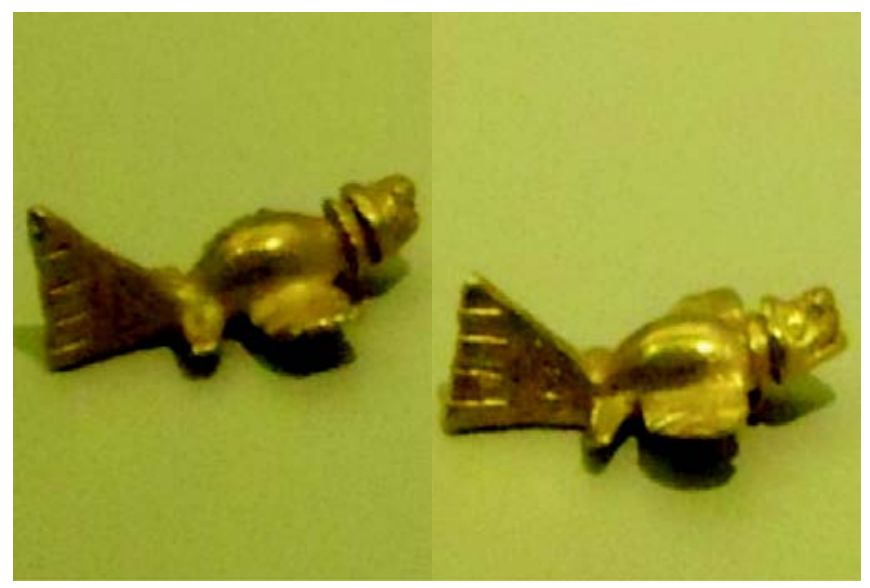

Figura 5. ¿Seres fantásticos, quiméricos, que reúnen aspectos de jaguares, peces voladores, peces e insectos? Skipers (lepidóptero). Cultura Tolima. Museo del Oro, Bogotá D.C. y en el otro de un insecto (Figuras 7,8 y 9); una vasija funeraria Tolima de un ser con cola de escorpión (Figura 10), un silbato Tairona con forma de escarabajo (Figura 11) y una piedra Tairona con forma de pupa (Figura 12).

En el primero de los platos Nariño (Figura 7), propiedad del Museo Arqueológico de la Casa del Marqués

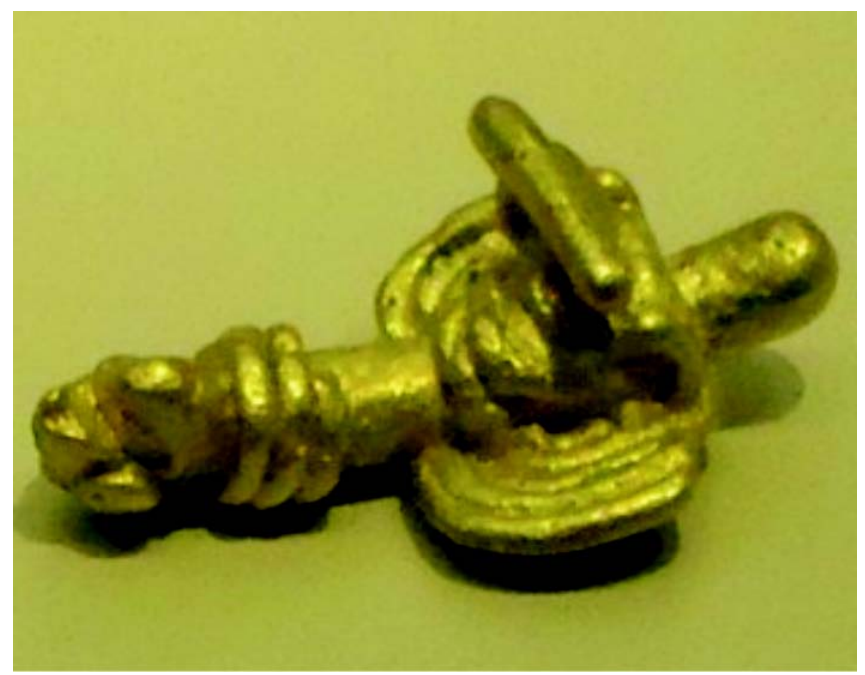

Figura 6. Animal quimérico con rasgos de insecto. Ofrenda Muisca. Museo del Oro, Bogotá D.C.

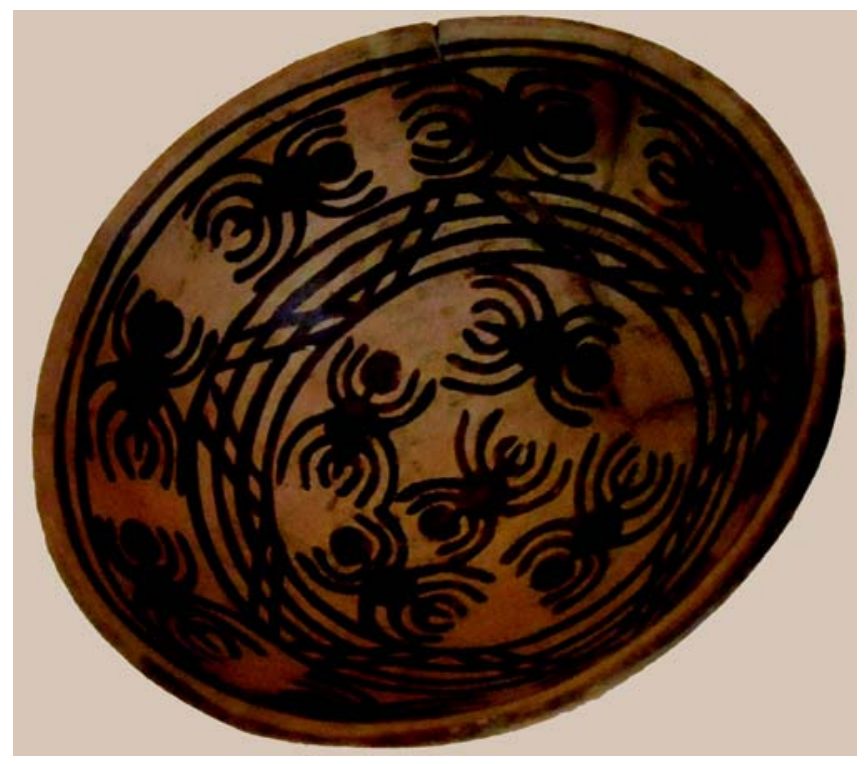

Figura 7. Plato funerario del altiplano nariñense del complejo cultural Tuza (I 250 - I500 d. C.). Museo Arqueológico de la Casa Marqués de San Jorge, Banco Popular, Bogotá D.C. 
de San Jorge, en Bogotá D.C. se ven en el centro del campo cinco arañas separadas por tres círculos de otras ocho que se encuentran en la periferia y que a su vez hacen contacto entre sí por una estrella de cinco puntas. En el segundo de ellos (Figura 8), de una colección particular, se observan en la mitad inferior de color ocre once arañas, mientras en la parte superior de color claro hay estilizaciones de aves. En el tercer plato (Figura 9) de una colección particular, se

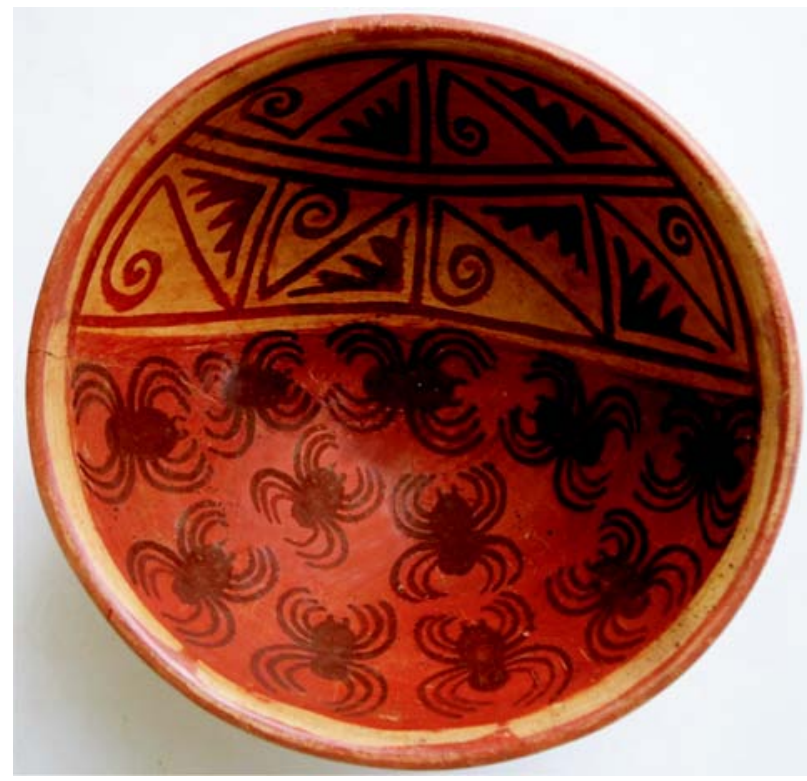

Figura 8. Plato funerario del altiplano nariñense del complejo cultural Tuza (I 250 - I500 d. C). Colección particular, Bogotá D.C.

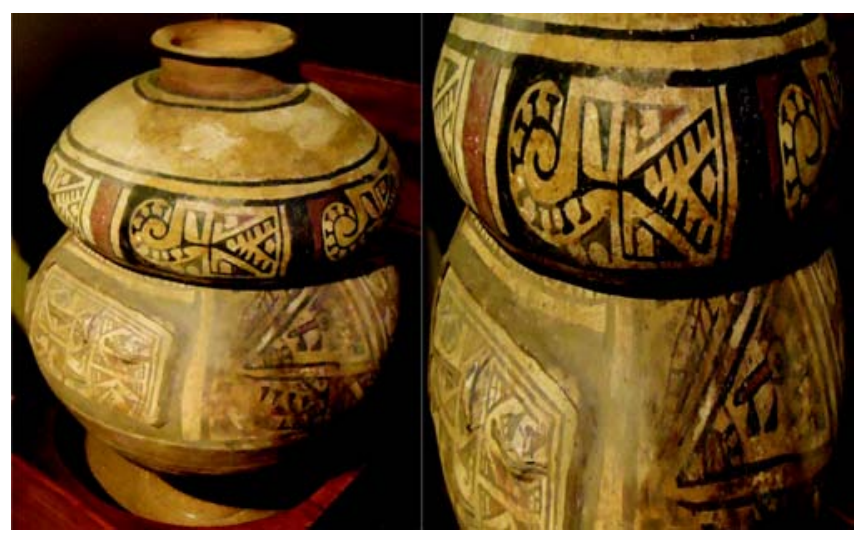

Figura 10.Vasija funeraria Tolima con figura que recuerda un escorpión. Colección particular, Bogotá D.C. aprecian cuatro insectos entre los brazos bífidos de una cruz solar.

En una vasija Tolima bellamente decorada en toda su superficie, se ve en uno de sus lados una figura estilizada que recuerda a un escorpión; mientras que en un pito de cerámica Tairona se aprecia un escarabajo y en una piedra cornalina está representada una pupa (Figuras 10, 11 y 12).

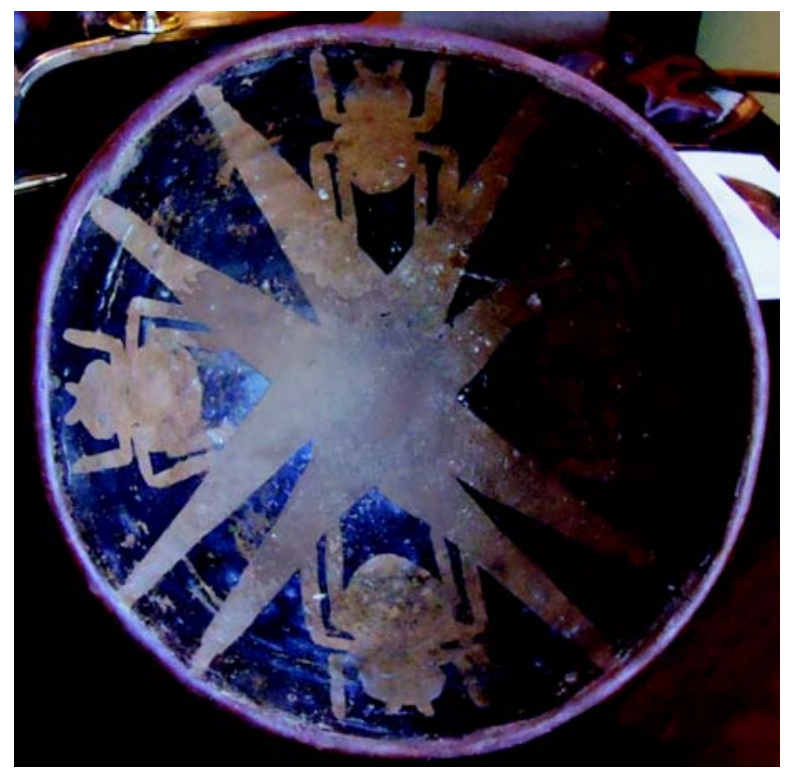

Figura 9. Plato funerario del altiplano nariñense del complejo cultural Tuza (I250 - I500 d. C.) que representa a un insecto. Colección particular, Bogotá D.C.

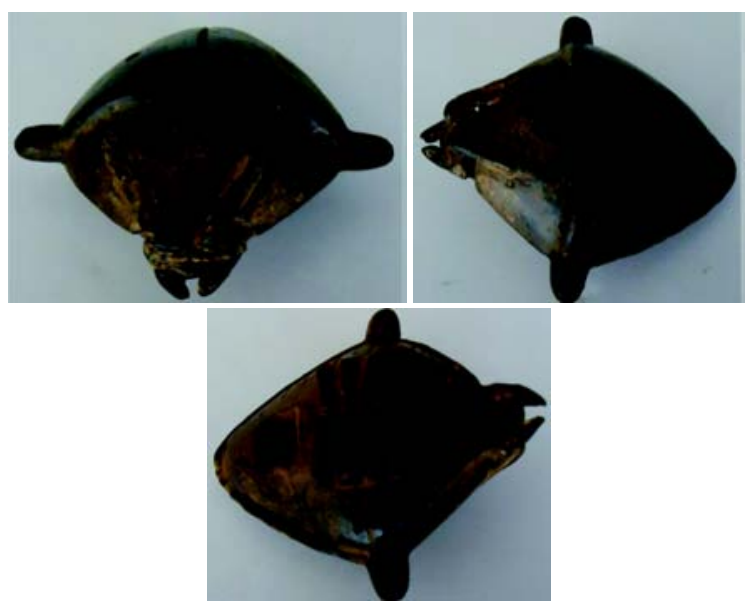

Figura I I. Pito en cerámica, Tairona, con forma de coleóptero (escarabajo). Colección particular, Bogotá D.C. 

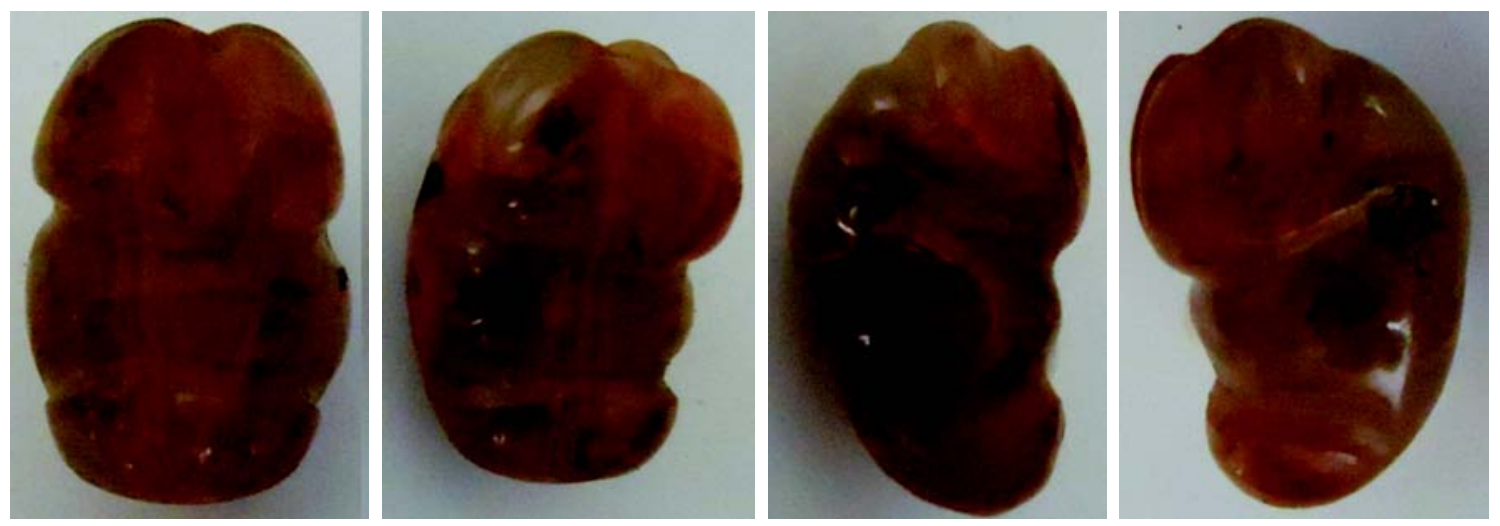

Figura I2. Pupa en piedra coralina, Tairona. Colección particular, Bogotá D.C.

\section{Discusión y conclusiones}

Los testimonios arqueológicos mostrados aquí revelan como los indígenas representaron con gran realismo no sólo a los artrópodos adultos (arañas e insectos), sino también a las crisálidas de las mariposas, las larvas y las pupas de insectos. Estos testimonios arqueológicos sugieren que sus mentes en posible modificación del estado de conciencia, crearon quimeras fantásticas en las que se mezclan algunas características de aves e insectos, mamíferos depredadores, peces voladores y reptiles.

Por el reducido tamaño de los objetos de oro aquí mostrados, ellos con seguridad fueron usados por las personas que los exhibían como adornos y talismanes, buscando cargarse de las características del insecto, de las larvas, de la crisálida y la metamorfosis de los seres quiméricos. La piedra cornalina que muestra un orificio debajo o cerca a lo que sería la cabeza de la pupa, lo más probable es que fuera usada para expresar un momento de la vida humana equiparable a ese estadio de algunos insectos que los indígenas reconocían como evolución de larvas, crisálidas, pupas e insectos adultos.

Las arañas en los platos funerarios Nariño señalan con alta probabilidad que los indígenas de estas culturas hayan compartido la idea que sobre las arañas y el inframundo que tuvieron los muiscas, como lo comentó el cronista antes transcrito. Los insectos entre la cruz solar de rayos bífidos en el plato funerario Nariño, señalan la relación que esa cultura hizo entre la descomposición cadavérica por la presencia de insectos y el renacimiento señalado por el sol. El escorpión en la parte superior del recipiente Tolima indiscutiblemente fue dibujado allí con el ánimo de proteger lo guardado en su interior.

La historia del estudio del conocimiento del hombre sobre los artrópodos en general, tiene unas etapas de diferentes duraciones: la primera y más larga corresponde al de las observaciones sobre el comportamiento y la vida social de los artrópodos, que generaron importantes prácticas no sólo de cuidados preventivos ante los riesgos de enfermedades ocasionadas por la ponzoña de algunos de ellos, sino a la elaboración de saberes gastronómicos alrededor del valor alimenticio o bien al uso de algunos de ellos o sus productos como medicinas y en la elaboración de mitologías. Estos conocimientos y cosmogonías se desarrollaron en casi todas las sociedades antiguas y premodernas, como es el caso de las indígenas de Colombia. Un ejemplo de particular interés sobre la utilidad que le dieron al conocimiento de los artrópodos fue el empleo de la cera de abejas sin aguijón, las Meliponini (tan abundantes en América prehispánica desde México hasta Argentina) en la técnica de cera pérdida tan empleada en la orfebrería de Ecuador, Colombia, Costa Rica y México.

Hubo necesidad ya no del conocimiento dado por la pura observación y la analogía, sino de uno obtenido 
por la experimentación y el pensamiento analítico para que el hombre supiera, desde finales del siglo XIX, de la condición de varios artrópodos en especial mosquitos, jejenes, piojos y garrapatas, como vectores de varios agentes infecciosos; y del papel que algunos de los artrópodos como los crustáceos, a principios del siglo XX, y los ácaros en la década de los sesenta del siglo XX, desempeñan en el fenómeno de la alergia que la medicina comenzó a esclarecer a principios del siglo XX. Este cuerpo de conocimiento no fue posible sino hasta cuando la medicina de las sociedades capi- talistas europeas desarrolló una sistemática experimentación analítica y construyó la mentalidad etiopatogénica.

\section{Lecturas recomendadas}

1. Fernández de Piedrahita L. Noticia historial de las conquistas del Nuevo Reino de Granada. Bogotá: Ministerio de Educación Nacional, Instituto Colombiano de Cultura Hispánica, Editorial Kelly; 1973. p. 64

2. Simón Pedro, F. Noticias historiales de las conquistas de Tierra Firme en las Indias Occidentales. Bogotá: Biblioteca banco Popular; 1981. p. 373. 